\title{
Simulation of Effects of Defects and Layers Thickness on the Performance of CIGS Solar Cells
}

\author{
A. KHADIR ${ }^{a, b, *}$ \\ ${ }^{a}$ Materials Science and Informatics Laboratory, University of Djelfa, Djelfa, Algeria \\ ${ }^{b}$ Laboratory of Metallic and Semiconducting Materials, University of Biskra, Biskra, Algeria \\ (Received November 20, 2019; in final form March 11, 2020)
}

A CIGS based solar cell structure with new proposed thicknesses of different layers has been carried out using Atlas module from SILVACO technology computer-aided design (T-CAD). The purpose of this paper is to enhance the efficiency by varying the thickness of each layer and optimizing the anti-reflective coating layer, as well. The optimization takes into account the defects in different layers and at interfaces. Our contribution focuses on reducing the layers' thicknesses and maintains the efficiency as high as possible with respect to experimental results. Short-circuit current density $J_{\mathrm{SC}}$, open-circuit voltage $V_{\mathrm{OC}}$, fill factor FF, and conversion efficiency $\eta$ were calculated and compared in each case in order to find out the best structure. The results showed that the optimal thicknesses of $0.11,0.25,0.03$, and $1.6 \mu \mathrm{m}$ for ARC layer, $\mathrm{ZnO}$ window layer, CdS buffer layer, and CIGS absorbent layer, respectively, give a conversion efficiency of $20.64 \%$, which is close to experimental one.

DOI: 10.12693/APhysPolA.137.1128

PACS/topics: CIGS, defects, SILVACO, solar cell, thin film

\section{Introduction}

Solar energy conversion has gained a large attention worldwide in recent decades due to its cleanness, renewability, and sustainability. A photovoltaic (PV) cell converts the solar energy into useful electricity through a photovoltaic effect process. Several PV cells exist in industry markets, all using semiconductors which interact with photons from the sun in order to generate an electric current. Amongst different photovoltaic cells, the market of thin-film solar cells progresses rapidly to substitute traditional silicon solar cells [1]. This is due to their high light absorption property and material consumption reduction. $\mathrm{CuInSe}_{2}$ (CIS) is a $\mathrm{I}-\mathrm{III}-\mathrm{VI}_{2}$ chalcopyrite type semiconductor used in thin film solar cell device applications. CIS has a direct band gap of $E_{g} \approx 1 \mathrm{eV}$ and has a strong light absorbability $\left(\alpha(1 \mathrm{eV})=1.7 \times 10^{4} \mathrm{~cm}^{-1}\right)$ under sunlight [2]. Gallium (Ga) incorporation in ternary CIS based materials allows the obtaining of the quaternary chalcopyrite semiconductor alloy CuInGaSe 2 . The latter is commonly noted CIGS, in which the tuning of the band gap is possible [3]. Hence, CIGS bandgap engineering improves the solar cells modules performance $[1,4]$. CIGS has undergone an immense research in recent years due to its recorded high efficiency, low cost, high stability, and high resistance to coring procedure [5-7]. $\mathrm{CuIn}_{1-x} \mathrm{Ga}_{x} \mathrm{Se}_{2}$ where $x$ represents the ratio $\mathrm{Ga} /(\mathrm{Ga}+\mathrm{In})$, allows thin film solar cells to achieve high efficiency without the environmental concerns of CdTe. Its direct bandgap is tunable from 1.02 to $1.68 \mathrm{eV}$ [8-11] by adjusting $x$. In a wide range of solar spectrum (400-1200 nm), a high absorption coefficient

\footnotetext{
*corresponding author; e-mail: Khadir71@yahoo.fr
}

can be achieved [12, 13]. A CIGS solar cell efficiency of $19.9 \%$ has been accomplished by NREL [14]. 22.90, 20.4, and $18.0 \%$ conversion efficiencies were reported in [15]. Another CIGS solar cell conversion efficiency which exceeds $21 \%[13,16,17]$ was obtained for a bandgap energy of $1.15 \mathrm{eV}$ for $x=0.3$. The highest theoretically expected efficiency was obtained for a material bandgap of $1.4 \mathrm{eV}$ $(x=0.7)$, which matches the absorption of the solar spectrum better. The experimental efficiency decreases when the bandgap is increased above $1.2 \mathrm{eV}$ due to material fabrication issues [18]. A record $23.35 \%$ efficiency was accomplished by solar frontier [19]. Minimization of the PV cell thicknesses leads to a desirable reduction in fabrication costs and time deposition. However, miniaturization of CIGS solar cells causes the appearance of problems that affect the efficiency, namely, recombination at back-contact and optical path's decrease which reduces the absorption of photons [20].

In this contribution, we have examined and optimized numerically an anti-reflective layer and studied the effect of defects on the CIGS based solar cells performance. In addition, different thicknesses of a window, buffer, and absorbent layers have been investigated. Atlas module from SILVACO T-CAD has been used in the numerical calculations.

The paper's organization is as follows. Section 2 presents a brief description of the adopted numerical simulation. The results are analyzed and discussed in Sect. 3. Section 4 contains the conclusions of our work.

\section{Materials, methods, and numerical simulation}

\subsection{Structure and ARC optimization}

Figure 1 displays the CIGS based solar cell geometry employed in this work, which is based on [21]. $n$ - ZnO, $i$-ZnO, $n$-CdS, and $p$-CIGS are the window, 


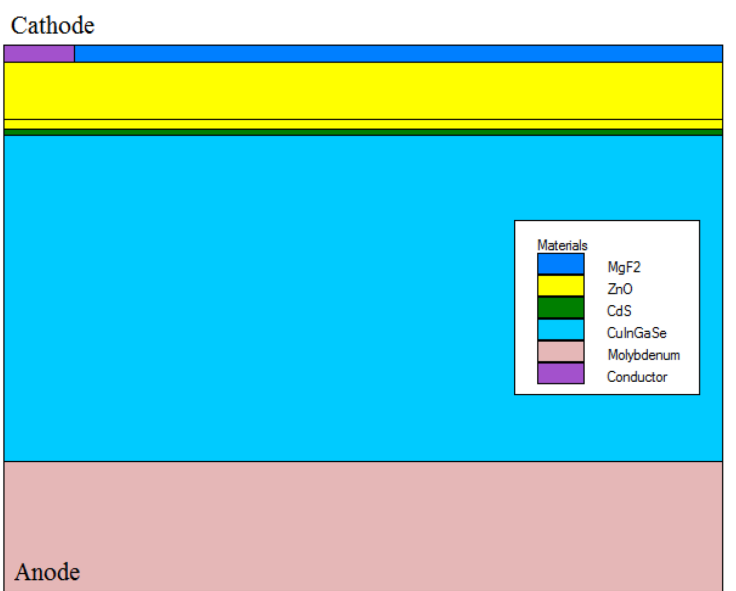

Fig. 1. Simulated CIGS solar cell structure.

intrinsic, buffer, and absorbent layers, respectively. $\mathrm{CuIn}_{1-x} \mathrm{Ga}_{x} \mathrm{Se}_{2}(x=0.4)$ is the active layer since it is responsible of absorption.

The energy band gap dependence with Ga mole fraction $x$ is modeled as follows [22]:

$$
E_{g}=0.67 x+0.99 \text {. }
$$

Light reflection at the surface of the solar cell is considered as a loss because it weakens its performance. In order to suppress this light reflection, the use of an antireflective coating layer (ARC) is of great importance. The reflectance at a quarter wavelength at the device's surface is given by

$$
R=\left(\frac{n_{0} n_{\mathrm{ZnO}: \mathrm{Al}}-n_{\mathrm{ARC}}^{2}}{n_{0} n_{\mathrm{ZnO}: \mathrm{Al}}+n_{\mathrm{ARC}}^{2}}\right)^{2},
$$

where $n_{0}, n_{\mathrm{ZnO} \text { Al }}$, and $n_{\mathrm{ARC}}$ are the refractive indices of the air, aluminum doped $\mathrm{ZnO}$, and anti-reflective coating layer, respectively.

The condition to get a zero reflectance is then

$$
n_{\mathrm{ARC}}^{2}=n_{0} n_{\mathrm{ZnO}: \mathrm{Al}} \text {. }
$$

In our system, $n_{0}=1$ and $n_{\mathrm{ZnO}} \mathrm{Al}=1.92$ at $550 \mathrm{~nm}$. From the previous equations, the reflectance equals zero when $n_{\mathrm{ARC}}=1.386$, which is close to the real value of the $\mathrm{MgF}_{2}$ refractive index (1.38) [23]. Hence, $\mathrm{MgF}_{2}$ is used as an ARC based material in this work.

\subsection{Numerical simulation}

A two-dimensional (2D) Atlas module from SILVACO [24] was used for simulating the behavior of the proposed design at room temperature. We focus the open-circuit voltage, short-circuit current density, fill factor, and conversion efficiency.

In the numerical simulation, the AM 1.5 spectrum was used at incident power density of $100 \mathrm{~mW} / \mathrm{cm}^{2}$. During simulation, all structural dimensions, perimeter, and physical models were kept unchanged. The optical parameters of device's materials were extracted from $[22,25]$.
The conversion efficiency is calculated using the following equation [26]:

$$
\eta[\%]=\frac{P_{\max }}{P_{\text {in }}}=\frac{J_{\mathrm{SC}} V_{\mathrm{OC}} \mathrm{FF}}{P_{\text {in }}},
$$

where $P_{\max }$ is the point at which the curve $J(V)$ gives the maximum power output, $P_{\text {in }}$ is the incident power of the solar spectrum, $J_{\mathrm{SC}}$ is the short-circuit current density, $V_{\mathrm{OC}}$ is the open-circuit voltage, and FF is the fill factor of the solar cell.

Table I summarizes the input data used in our study, which is taken from the available literature.

Here $N_{\text {DG }}$ is the Gaussian donor-like defect density, $N_{\text {AG }}$ denotes Gaussian acceptor-like defect density. $E_{\mathrm{D}}$ represents donor-like peak energy position and $E_{\mathrm{A}}$ is the acceptor-like peak energy position. $W_{\mathrm{G}}$ is the standard energy deviation, $\sigma_{e}$ denotes electron captor crosssection, $\sigma_{h}$ represents hole captor cross-section, and $\Delta E_{\mathrm{C}}$ is the conduction band offset.

\section{Results and discussion}

The photogenerated current density $J$, open-circuit voltage, fill factor, and conversion efficiency of a CIGS based solar cell with and without $\mathrm{MgF}_{2}$ ARC layer and defects have been investigated. The results are carried out using Atlas module from SILVACO T-CAD. Figure 2 depicts the effect of both defects and $\mathrm{MgF}_{2}$ ARC layer on the different electric parameters of the proposed solar cell. As shown in Fig. 2a, the use of ARC layer induces an important increase in the short-current density. We notice that $J_{\mathrm{SC}}$ increases from 31.56 to $33.98 \mathrm{~mA} / \mathrm{cm}^{2}$ $\left(\Delta J_{\mathrm{SC}}=2.42 \mathrm{~mA} / \mathrm{cm}^{2}\right.$ equivalent to $\left.7.67 \%\right)$ for device with defects when using $0.11 \mu \mathrm{m} \mathrm{MgF}$ layer thickness. In the case of device without defects, the shortcurrent density increases from 34.15 to $36.7 \mathrm{~mA} / \mathrm{cm}^{2}$ $\left(\Delta J_{\mathrm{SC}}=2.55 \mathrm{~mA} / \mathrm{cm}^{2}\right.$ which means $\left.7.47 \%\right)$.
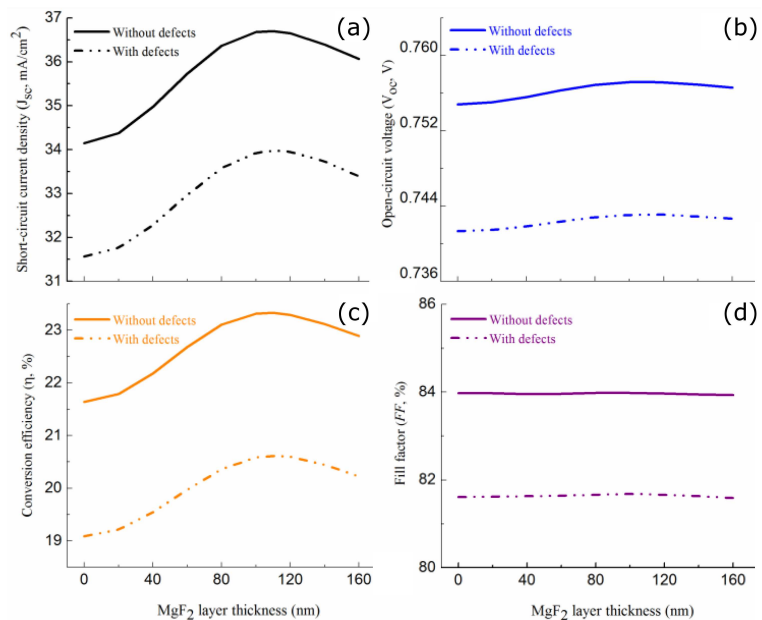

Fig. 2. Short-current density (a), open-circuit voltage (b), conversion efficiency (c), and fill factor (d) as a function of $\mathrm{MgF}_{2} \mathrm{ARC}$ layer thickness with and without defects. 
Simulation input data of the $\mathrm{ZnO} / \mathrm{CdS} /$ CIGS thin film solar cell.

\begin{tabular}{|c|c|c|c|c|}
\hline General device properties [27] & \multicolumn{2}{|c|}{ Front } & \multicolumn{2}{|c|}{ Back } \\
\hline $\begin{array}{l}\text { barrier height } \Phi_{b}[\mathrm{eV}] \\
\text { surf. recomb. velocity } S_{e}, S_{h}[\mathrm{~cm} / \mathrm{s}] \\
\text { reflectivity }\end{array}$ & \multicolumn{2}{|c|}{$\begin{array}{c}\Phi_{b n}=0 \\
10^{7} \\
0.05\end{array}$} & \multicolumn{2}{|c|}{$\begin{array}{c}\Phi_{b p}=0.2 \\
10^{7} \\
0.8\end{array}$} \\
\hline Layer properties & $\mathrm{ZnO}: \mathrm{Al}$ & $i-\mathrm{ZnO}$ & $n$-CdS & $p$-CIGS \\
\hline dielectric constant & 9 & 9 & 10 & 13.6 \\
\hline band gap $[\mathrm{eV}]$ & 3.3 & 3.3 & 2.45 & 1.26 \\
\hline electron affinity $[\mathrm{eV}]$ & 4.48 & 4.48 & 4.28 & 4.58 \\
\hline conduction band effective density of states $\left[\mathrm{cm}^{-3}\right]$ & $2.2 \times 10^{18}$ & $2.2 \times 10^{18}$ & $2.2 \times 10^{18}$ & $2.2 \times 10^{18}$ \\
\hline valence band effective density of states $\left[\mathrm{cm}^{-3}\right]$ & $1.8 \times 10^{19}$ & $1.8 \times 10^{19}$ & $1.8 \times 10^{19}$ & $1.8 \times 10^{19}$ \\
\hline electron, hole mobilities $\left[\mathrm{cm}^{2} \mathrm{~V}^{-1} \mathrm{~s}^{-1}\right]$ & $100 / 25$ & $100 / 25$ & $100 / 25$ & $100 / 25$ \\
\hline doping concentrations $n, p\left[\mathrm{~cm}^{-3}\right]$ & $\mathrm{n}: 5 \times 10^{18}$ & $\mathrm{n}: 5 \times 10^{17}$ & $\mathrm{p}: 5 \times 10^{17}$ & $\mathrm{n}: 10^{16}$ \\
\hline \multicolumn{5}{|l|}{ Gaussian (mid-gap) defect states [27] } \\
\hline$N_{\mathrm{DG}}, N_{\mathrm{AG}}\left[\mathrm{cm}^{-3}\right]$ & D: $10^{17}$ & D: $10^{17}$ & A: $4 \times 10^{18}$ & D: $10^{14}$ \\
\hline$E_{\mathrm{D}}, E_{\mathrm{A}}[\mathrm{eV}]$ & mid-gap & mid-gap & mid-gap & mid-gap \\
\hline$W_{\mathrm{G}}[\mathrm{eV}]$ & 0.1 & 0.1 & 0.1 & 0.1 \\
\hline$\sigma_{e}, \sigma_{h}\left[\mathrm{~cm}^{2}\right]$ & $10^{-12} / 10^{-15}$ & $10^{-12} / 10^{-15}$ & $10^{-17} / 10^{-12}$ & $5 \times 10^{-13} / 10^{-15}$ \\
\hline Interface Gaussian defect states & \multicolumn{2}{|c|}{$i-\mathrm{ZnO} / \mathrm{CdS}$} & \multicolumn{2}{|c|}{ CdS $/$ CIGS } \\
\hline$\Delta E_{\mathrm{C}}[\mathrm{eV}]$ & \multirow{5}{*}{\multicolumn{2}{|c|}{-0.2}} & \multirow{2}{*}{\multicolumn{2}{|c|}{$\begin{array}{c}0.3 \\
10^{12}\end{array}$}} \\
\hline$N_{t}\left[\mathrm{~cm}^{-3}\right]$ & & & & \\
\hline$E_{\mathrm{D}}, E_{\mathrm{A}}[\mathrm{eV}]$ & & & \multicolumn{2}{|c|}{ mid-gap } \\
\hline$W_{\mathrm{G}}[\mathrm{eV}]$ & & & \multicolumn{2}{|c|}{0.1} \\
\hline$\sigma_{e}, \sigma_{h}\left[\mathrm{~cm}^{2}\right]$ & & & \multicolumn{2}{|c|}{$5 \times 10^{-13} / 10^{-15}$} \\
\hline
\end{tabular}

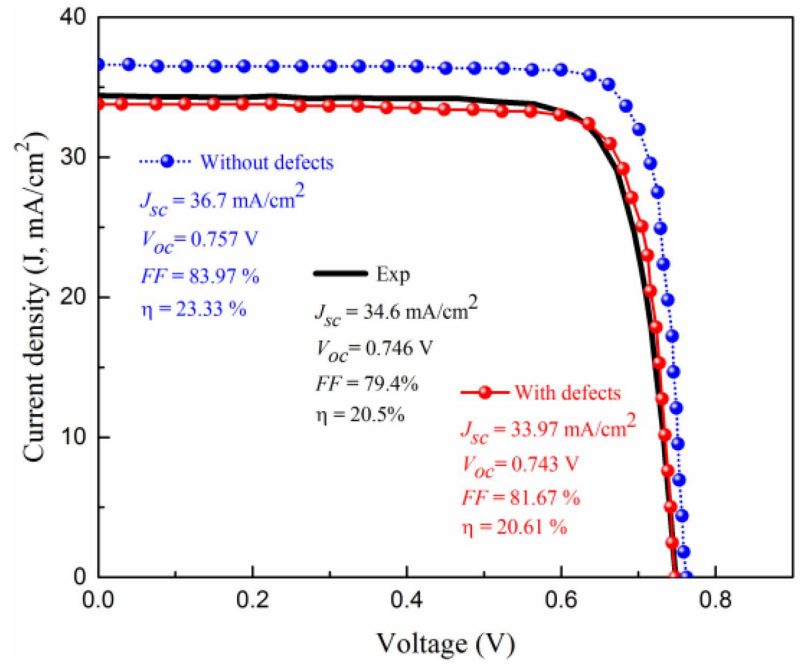

Fig. 3. Current density $J$ vs. anode voltage.

For device with defects, the efficiency increases from 19.09 without ARC to $20.61 \%$ with the use of $0.11 \mu \mathrm{m}$ $\mathrm{MgF}_{2}$ layer (augmentation of $7.96 \%$ ) as depicted in Fig. 2c. For device without defects, the efficiency increases from 21.64 (without ARC) to $23.33 \%$ with the use of $0.11 \mu \mathrm{m} \mathrm{MgF}$ layer (augmentation of $7.81 \%$ ).

The effect of ARC layer on both $V_{\mathrm{OC}}$ and $\mathrm{FF}$ is negligible as illustrated in Fig. $2 \mathrm{~b}$ and $\mathrm{d}$, respectively. The increment in $J_{\mathrm{SC}}$ and $\eta$ is caused by the suppression of reflected light at the cell surface via $\mathrm{MgF}_{2}$ layer which al- lowed more carriers to be photogenerated. Figure 2 indicates that the results are too optimistic when the defects are not taken into account. $J_{\mathrm{SC}}$ decreases by about $7.5 \%$ and $\eta$ decreases by about $11.7 \%$ when defects are introduced.

Figure 3 shows the current density as a function of anode voltage for devices with and without defects (containing $\mathrm{MgF}_{2}$ layer as $\mathrm{ARC}$ ) in comparison with experimental device from [21]. We notice that the curves of devices with defects and experimental are nearly identical.

Figure 4 presents the quantum efficiency as a function of wavelength for devices with defects, without defects, and experimental case. The analysis of this figure indicates that the quantum efficiency of device with defect and that of experimental are close to each other. Figures 3 and 4 confirm that taking into account defects gives more credibility to simulation results.

Figure 5 exhibits the evolution of short-current density and open-circuit voltage as a function of defects in CIGS. A defect of donor density from $10^{14}$ to $10^{15} \mathrm{~cm}^{-3}$ was applied. We remark that both $J_{\mathrm{SC}}$ and $V_{\mathrm{OC}}$ decrease with the augmentation of defect density. $J_{\mathrm{SC}}$ drops from 33.98 to $32.75 \mathrm{~mA} / \mathrm{cm}^{2}$ (a decrease of $03.62 \%$ ) for a defect density from $10^{14}$ to $10^{15} \mathrm{~cm}^{-3}$, respectively. From its side, $V_{\mathrm{OC}}$ tumbles from 0.743 to $0.704 \mathrm{~V}$ (a diminution of about $5.25 \%$ ).

The conversion efficiency and the fill factor as a function of CIGS defects density are depicted in Fig. 6. $\eta$ and FF from their side, underwent a diminution of $13.25 \%$ (from 20.61 to $17.88 \%$ ) and $5.1 \%$ (from 81.68 


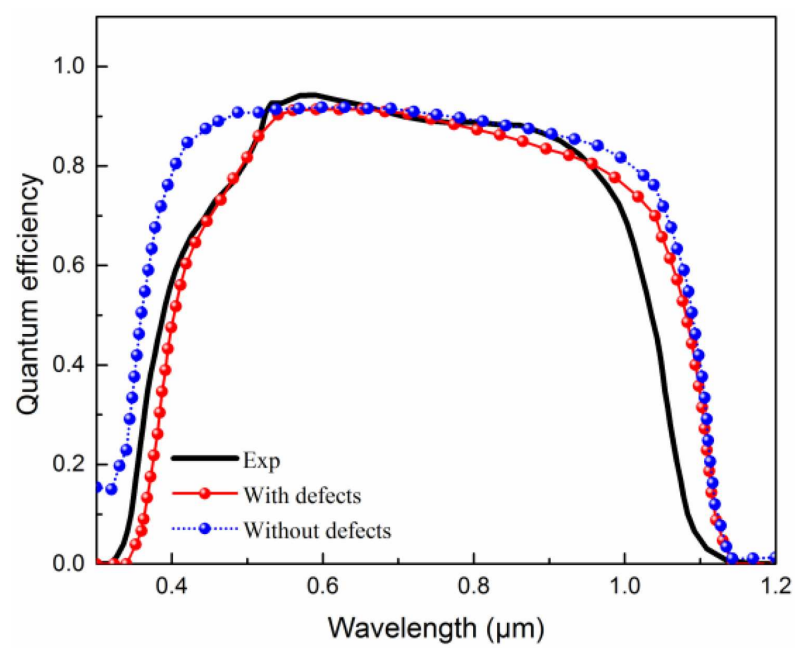

Fig. 4. Quantum efficiency vs. wavelength.

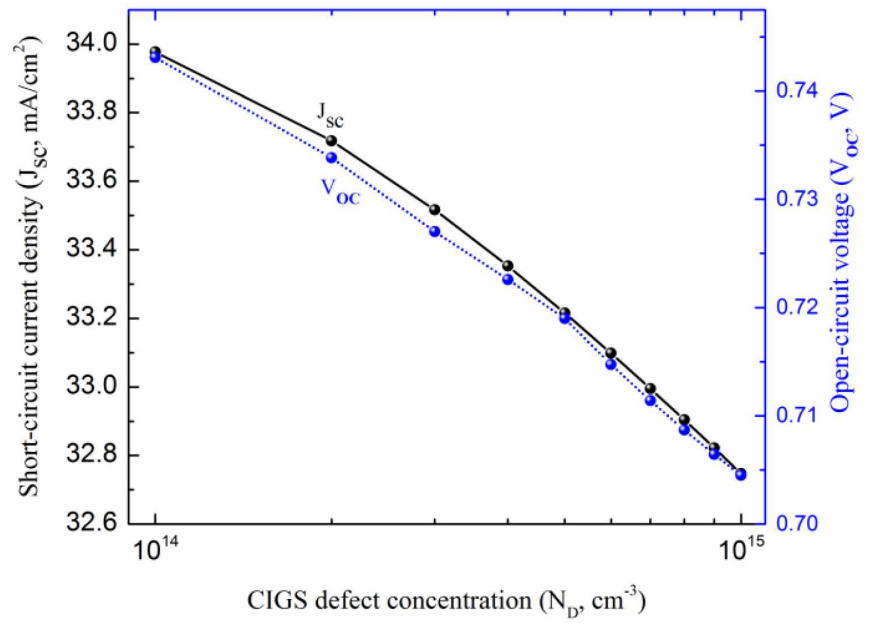

Fig. 5. Short-circuit current density and open-circuit voltage vs. CIGS defect density.

to $77.53 \%$ ), respectively. The presence of defects provides recombination pathways, which act as recombination centers (energy levels in the band gap) that trap the photogenerated carriers. Therefore, their lifetime in the absorbent region is reduced leading to a diminution in the photogenerated current density. As the defect density increases, the number of recombination centers increases, as well, and thus the loss in current density becomes more significant, which degrades the conversion efficiency.

The plot of $J_{\mathrm{SC}}$ and $V_{\mathrm{OC}}$ as a function of $\mathrm{ZnO}$ :Al window layer thickness is illustrated in Fig. 7. Thicknesses in the range from 0.05 to $0.5 \mu \mathrm{m}$ are chosen in order to study their effect on the main electric parameters of the solar cell underload. The plot reveals a decrease in $J_{\mathrm{SC}}$ as the window layer thickness increases. $J_{\mathrm{SC}}$ drops from 34.65 to $33.68 \mathrm{~mA} / \mathrm{cm}^{2}$ for 0.05 to $0.5 \mu \mathrm{m} \mathrm{ZnO:Al} \mathrm{thick-}$ nesses, respectively (a decrease of about $2.8 \%$ ) while $V_{\mathrm{OC}}$ appears to be invariant.

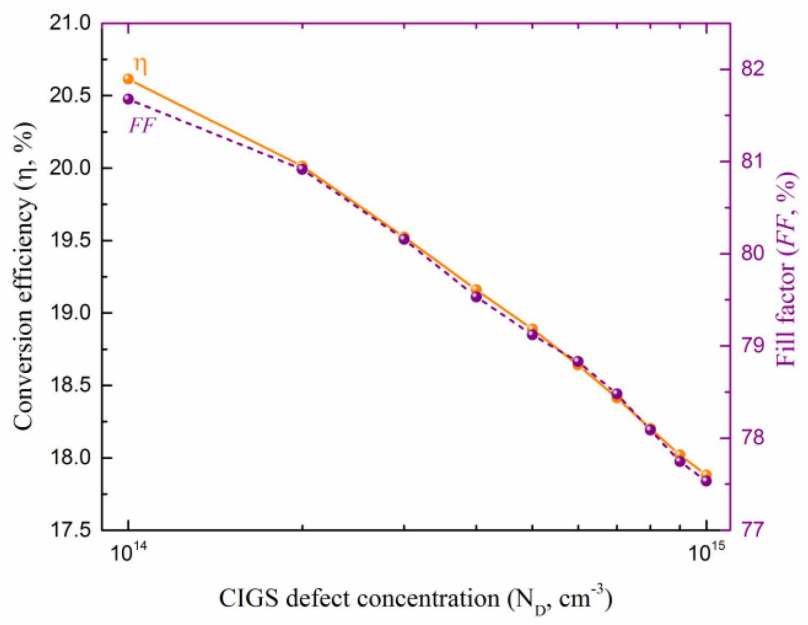

Fig. 6. Conversion efficiency and fill factor vs. CIGS defect density.

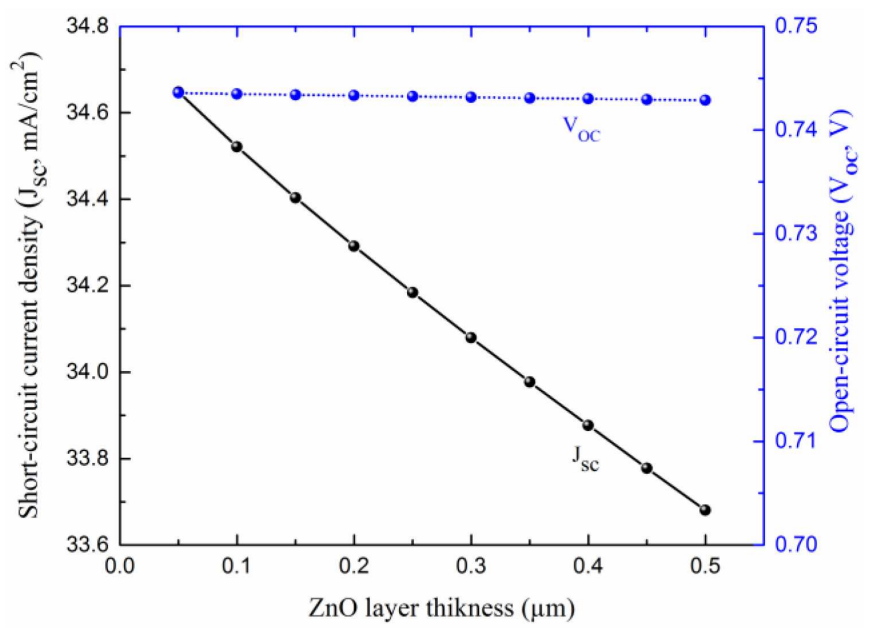

Fig. 7. Short-circuit current density and open-circuit voltage vs. $\mathrm{ZnO}$ :Al layer thickness.

Figure 8 represents the variation of conversion efficiency and fill factor as a function of suggested window layer thicknesses. We remark that $\eta$ drops from 21.04 (with $0.05 \mu \mathrm{m} \mathrm{ZnO:Al} \mathrm{thickness)} \mathrm{to} 20.43 \%(0.5 \mu \mathrm{m}$ thickness $\mathrm{ZnO}: \mathrm{Al}$ thickness). This means a decrease of about $2.9 \%$, whereas FF is hardly affected. The increase of window thickness has a consequence of electron-hole pairs creation and thus a decrease in conversion efficiency. Thin window layer is not desirable since series resistance becomes more important. Therefore, optimizing $\mathrm{ZnO}: \mathrm{Al}$ electrically and optically is needed to have a high efficiency as reported [28].

It is important to view how the electrical parameters are affected by the use of different thicknesses of buffer layer. In this regard, the variation of $J_{\mathrm{SC}}$ and $V_{\mathrm{OC}}$ is represented in Fig. 9. It is obvious that as the CdS thickness augments, the short-circuit density decreases while the 


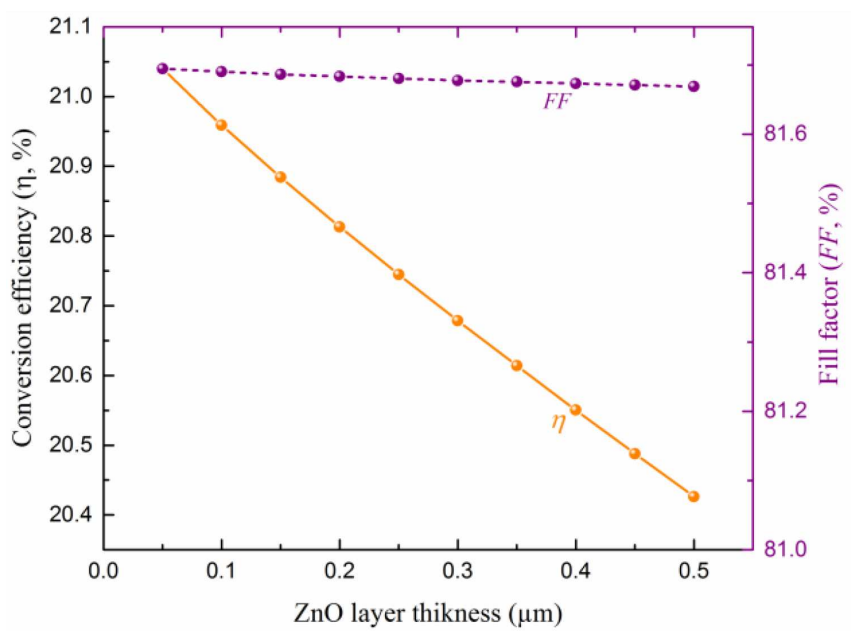

Fig. 8. Conversion efficiency and fill factor vs. $\mathrm{ZnO}: \mathrm{Al}$ layer thickness.

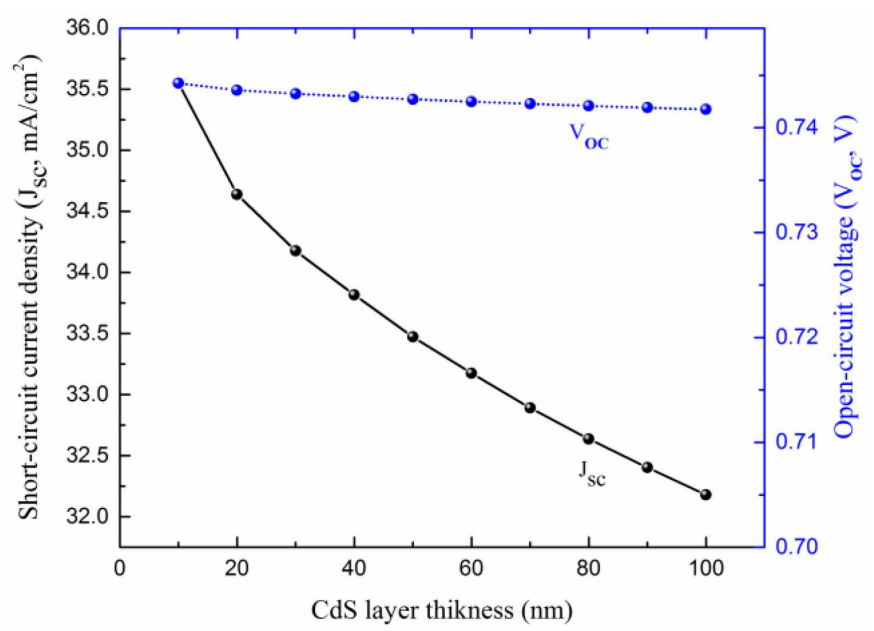

Fig. 9. Short-circuit current density and open-circuit voltage vs. CdS layer thickness.

open-circuit voltage remains constant. When increasing CdS thickness from 0.01 to $0.1 \mu \mathrm{m}, J_{\mathrm{SC}}$ drops from 35.55 to $32.18 \mathrm{~mA} / \mathrm{cm}^{2}$ (a decrease of about $9.48 \%$ ). On the other side, the conversion efficiency drops with the increase of CdS layer thickness. It decreases from $21.63 \%$ for a $0.01 \mu \mathrm{m}$ CdS thickness to $19.45 \%$ for a $0.1 \mu \mathrm{m} \mathrm{CdS}$ thickness ( about 10.08\%), whereas the fill factor seems to be not affected as shown in Fig. 10. In reality, the larger the buffer layer, the more photons are absorbed within it. Thus, the number of photons reaching the absorbent layer (CIGS) decreases leading to a loss in conversion efficiency [29]. For this reason, it is desirable to minimize the thickness of the buffer layer in order to make the photons number that are considered to reach the absorbent layer as high as possible. Thin CdS prevent minority carriers from recombination since their lifetime in it is very short.

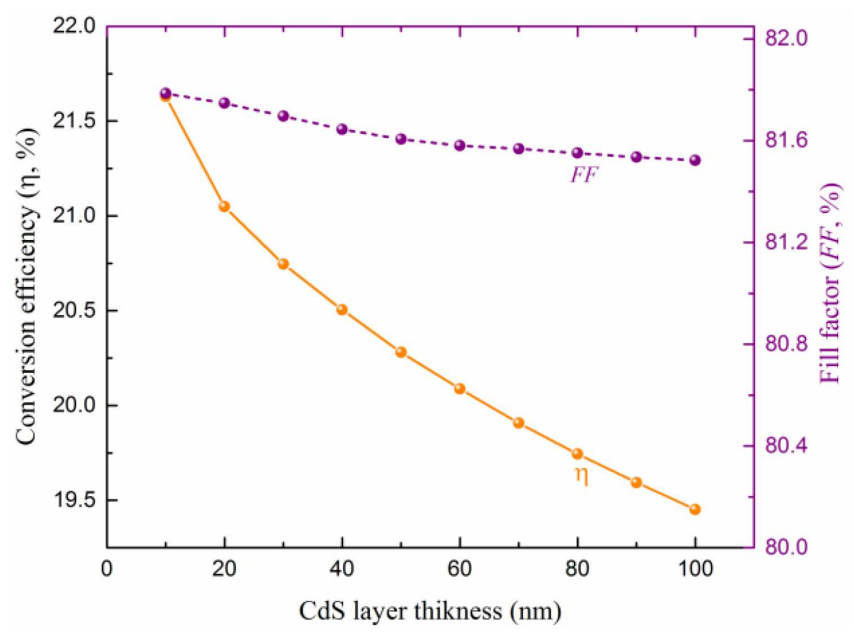

Fig. 10. Conversion efficiency and fill factor vs. CdS layer thickness.

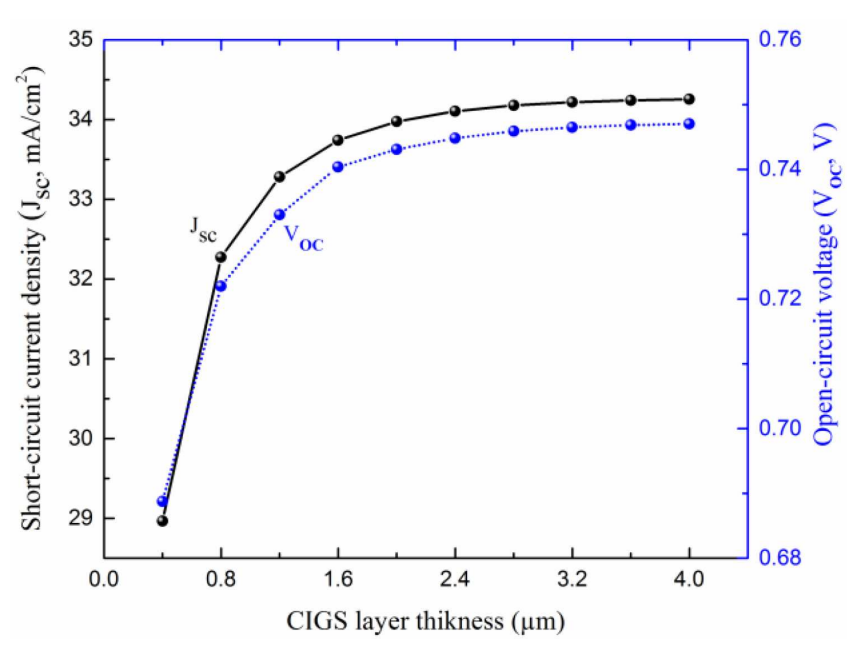

Fig. 11. Short-circuit current density and open-circuit voltage vs. CIGS layer thickness.

Let us turn our attention now to the CIGS active region. In this regard, we consider thicknesses going from 0.4 to $4 \mu \mathrm{m}$. For each thickness, electric parameters are extracted, compared, then analyzed attentively in order to find out the best enhancement in conversion efficiency at a lowest CIGS thickness. Figure 11 exhibits the shortcurrent density and open-circuit voltage as a function of CIGS thickness. We remark that both $J_{\mathrm{SC}}$ and $V_{\mathrm{OC}}$ increase when the CIGS layer thickness is increased. $J_{\mathrm{SC}}$ increases from $28.97 \mathrm{~mA} / \mathrm{cm}^{2}$ with CIGS layer thickness of $0.4 \mu \mathrm{m}$ to $34.26 \mathrm{~mA} / \mathrm{cm}^{2}$ with $4 \mu \mathrm{m}$ CIGS layer thickness (enhancement about 18.26\%). From its side, $V_{\mathrm{OC}}$ increases from 0.689 to $0.747 \mathrm{~V}$ (about $08.42 \%$ ). When the absorber thickness becomes larger, the optical path increases and hence more photons are absorbed which means more electron-hole pairs are generated and hence the current density augments. 


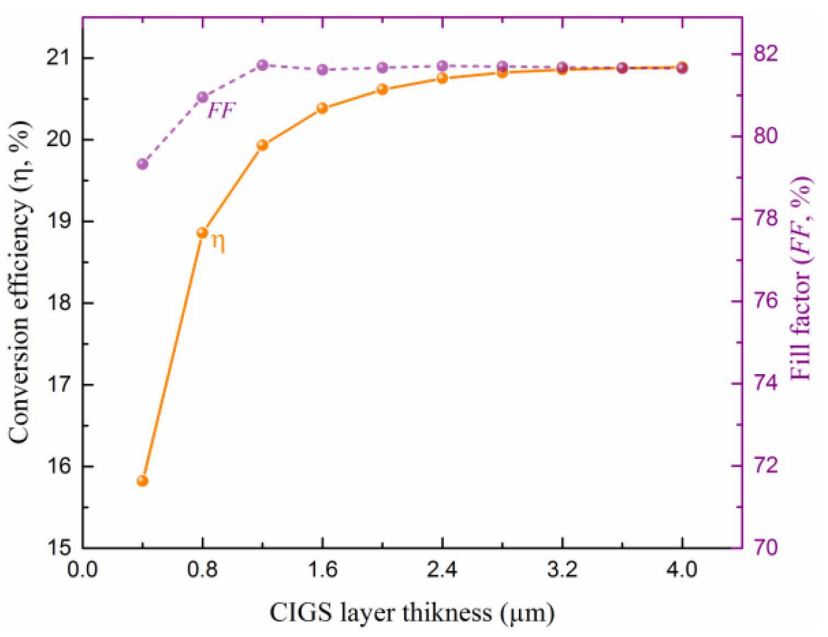

Fig. 12. Conversion efficiency and fill factor vs. CIGS layer thickness.

The conversion efficiency and fill factor as a function of CIGS layer thickness are depicted in Fig. 12. The analysis of the graph shows that the efficiency underwent a remarkable enhancement until CIGS layer reaches a thickness of $1.6 \mu \mathrm{m}$, which is in good accord with [30]. From 0.4 to $1.6 \mu \mathrm{m}$ thicknesses, we note an efficiency enhancement about $28.82 \%$ ( $\eta$ rises from 15.82 to $20.38 \%$ ). After the latter thickness, the enhancement becomes lower, from 1.6 to $2.4 \mu \mathrm{m}$, i.e. an enhancement about $1.8 \%$ is attained ( $\eta$ rises from 20.38 to $20.75 \%$ ). When the CIGS thickness varied from 2.4 to $4 \mu \mathrm{m}$, a negligible enhancement of about $0.7 \%$ is reached ( $\eta$ rises from 20.75 to $20.89 \%$ ). The fill factor increases from 79.33 to $81.74 \%$ (CIGS thickness varied from 0.4 to $1.2 \mu \mathrm{m}$ ) and then it becomes constant.

\section{Conclusions}

Effects of anti-reflective coating, defects, and thickness of different layers of a based CIGS solar cell structure on the main photovoltaic parameters, specifically $J_{\mathrm{SC}}, V_{\mathrm{OC}}$, $\mathrm{FF}$, and $\eta$ were carried out using Atlas module from SILVACO T-CAD. Simulation results show that the use of a $0.11 \mu \mathrm{m}$ ARC $\mathrm{MgF}_{2}$ monolayer enhances the conversion efficiency by about $7.8 \%$. On the other hand, results prove that defects harm the solar cell performance significantly. A donor defect density of $10^{14} \mathrm{~cm}^{-3}$ within CIGS layer leads to a decrease of about $11.66 \%$ in the conversion efficiency in comparison with device without defects. In addition, it is found that by increasing the thickness of each of the window or buffer layers, the conversion efficiency underwent a remarkable decrease. Increasing the absorbent layer thickness enhances the conversion efficiency considerably. Interesting optimal parameters for each layer were determined in order to make conversion efficiency close to experimental and to reduce the layers' thicknesses as well. Our results show that the best structure has a $0.11 \mu \mathrm{m} \mathrm{ARC} \mathrm{MgF}_{2}$ thickness, $10^{14} \mathrm{~cm}^{-3}$ donor defects density in CIGS, and $\mathrm{ZnO}: \mathrm{Al}, i-\mathrm{ZnO}$, CdS, and CIGS thicknesses of $0.25,0.06,0.03$, and $1.6 \mu \mathrm{m}$, respectively, which gives a $20.64 \%$ conversion efficiency.

\section{Acknowledgments}

The author acknowledges colleagues and individuals for their help and support to achieve this work.

\section{References}

[1] X. Yuan, X. Ma, J. Liao, F. Ye, L. Shao, F. Peng, J. Zhang, ACS Sustain. Chem. Eng. 5, 7325 (2017).

[2] S. Theodoropoulou, D. Papadimitriou, K. Anestou, C. Cobet, N. Esser, Semicond. Sci. Tech. 24, 015014 (2008).

[3] S.H. Wei, S.B. Zhang, A. Zunger, Appl. Phys. Lett. 72, 3199 (1998).

[4] M.A. Contreras, K. Ramanathan, J. AbuShama, F. Hasoon, D.L. Young, B. Egaas, R. Noufi, Prog. Photovolt. 13, 209 (2005).

[5] P. Jackson, R. Wuerz, D. Hariskos, E. Lotter, W. Witte, M. Powalla, Phys. Status Solidi R. 10, 583 (2016).

[6] H.R. Moutinho, S. Johnston, B. To, C.S. Jiang, C. Xiao, P. Hacke, J. Moseley, J. Tynan, N.G. Dhere, M.M. Al-Jassim, Sol. Energy 161, 235 (2018).

[7] X. Lin, H. Li, F. Qu, H. Gu, W. Wang, Sol. Energy 171, 130 (2018).

[8] B. Reinhold, M. Schmid, D. Greiner, M. Schüle, D. Kieven, A. Ennaoui, M.Ch. Lux-Steiner, Prog. Photovolt. 23, 1929 (2015).

[9] M. Gloeckler, J.R. Sites, J. Phys. Chem. Solids 66, 1891 (2005).

[10] M. Kemell, M. Ritala, M. Leskelä, Crit. Rev. Solid State 30, 1 (2005).

[11] O. Lundberg, M. Edoff, L. Stolt, Thin Solid Films 480-481, 520 (2005).

[12] S. Ouedraogo, R. Sam, F. Ouedraogo, M.B. Kebre, F. Zougmore, J.M. Ndjaka, in: IEEE AFRICON Conf., Pointe-Aux-Piments (Mauritius), 2013, p. 95.

[13] N. Bednar, N. Severino, N. Adamovic, Appl. Sci. 5, 1735 (2015)

[14] I. Repins, M.A. Contreras, B. Egaas, C. DeHart, J. Scharf, C.L. Perkins, B. To, R. Noufi, Prog. Photovolt. 16, 235 (2008).

[15] L. Zortea, S. Nishiwaki, T.P. Weiss, S. Haass, J. Perrenoud, L. Greuter, T. Feurer, G. Palaniswamy, S. Buecheler, A.N. Tiwari, Sol. Energy 175, 25 (2018).

[16] Y. Hirai, Y. Kurokawa, A. Yamada, Jpn. J. Appl. Phys. 53, 012301 (2014).

[17] S. Lee, E.S. Lee, T.Y. Kim, J.S. Cho, Y.J. Eo, J.H. Yun, A. Cho, Sol. Energy Mater. Sol. Cells 141, 299 (2015).

[18] A. Aissatt, H. Arbouz, J.P. Vilcot, Sol. Energy Mater. Sol. Cells 180, 381 (2018).

[19] Solar Frontier Achieves, World Record Thin-Film Solar Cell Efficiency of $23.35 \%$. 
[20] M. Gloecker, J.R. Sites, J. Appl. Phys. 98, 103703 (2005).

[21] J. Nishinaga, T. Koida, S. Ishizuka, Y. Kamikawa, H. Takahashi, M. Iioka, H. Higuchi, Y. Ueno, H. Shibata, S. Niki, Appl. Phys. Express 10, 092301 (2017).

[22] A. Loubat, C. Eypert, F. Mollica, M. Bouttemy, N. Naghavi, D. Lincot, A. Etcheberry, Appl. Surf. Sci. B 421, 643 (2017).

[23] S.S. Batsanov, E.D. Ruchkin, I.A. Poroshina, Refractive Indices of Solids, Springer, Singapore 2016.

[24] Silvaco, Atlas User's Manual.

[25] R. Carron, E. Avancini, T. Feurer, et al., Sci. Technol. Adv. Mat. 19, 396 (2018).
[26] S.W. Feng, C.M. Lai, C.H. Chen, W.C. Sun, L.W. Tu, J. Appl. Phys. 108, 093118 (2010).

[27] M. Gloeckler, A.L. Fahrenbruch, J.R. Sites, "Numerical Modeling of CIGS and CdTe Solar Cells: Setting the Baseline", in: 3rd World Conf. of Photovoltaic Energy Conversion, 2003, poster, p. 491.

[28] M.M. Islam, S. Ishizuka, A. Yamada, K. Matsubara, S. Niki, T. Sakurai, K. Akimoto, Appl. Surf. Sci. 257, 4026 (2011).

[29] P. Chelvanathan, M.I. Hossain, N. Amin, Curr. Appl. Phys. 10, S387 (2010).

[30] X. Zhao, M. Lu, M.J. Koeper, R. Agrawal, J. Mater. Chem. A 4, 7390 (2016). 